\title{
Hyperbaric 2\% Lignocaine In Spinal Anaesthesia - An Excellent Option For Day Care Surgeries
}

\author{
Dr. Sweety Purushotham $\mathrm{N}^{1}$, Dr. Abhin Devdas ${ }^{2}$, Dr. Pradeep Javedar ${ }^{3}$, \\ Dr. A.V.Mallikarjuna ${ }^{4}$

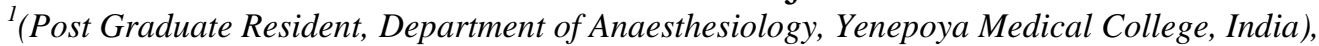 \\ ${ }^{2}$ (Post Graduate Resident, Department of Anaesthesiology, A.J. Institute of Medical Sciences, India), \\ ${ }^{3}$ (Post Graduate Resident, Department of Pharmacology, M.R. Medical College, India), \\ ${ }^{4}$ (Professor, Department of Anaesthesiology, Yenepoya Medical College, India)
}

\begin{abstract}
Hyperbaric Lignocaine is a popular spinal anaesthetic agent especially in short duration surgeries because of its faster onset, intense sensory and motor block of moderate duration and recovery profile. Lower concentrations of hyperbaric lignocaine are used for this purpose. Sixty ASA physical status I \& II patients, both male and female posted for various elective surgeries under spinal anaesthesia admitted in our hospital were studied. The patients were given $2 \%$ hyperbaric lignocaine $2 \mathrm{ml}$ for spinal anaesthesia using 25 G Quincke's spinal needle after uniform pre-medication and pre-loading with $500 \mathrm{ml}$ lactated Ringer's solution iv fluid. The patients of age group 18 to 65 years undergoing lower limb and abdominal surgeries were selected, the onset time of sensory and motor block, duration of motor block, maximum height of block was noted. Their hemodynamic parameters were stable and not clinically significant compared to vitals of other time period although statistically significant. Dermatomal level reached was T8-10 in majority. Serious adverse effects or neurological deficits associated with the drug did not occur in any patient in this study. We found $2 \%$ hyperbaric lignocaine to be an effective spinal anaesthetic agent for day care surgeries.
\end{abstract}

Keywords: Hyperbaric lignocaine, 2\% Lignocaine Heavy, Spinal Anaesthesia, Day Care Surgery

\section{INTRODUCTION}

Spinal anaesthesia has been a safe and popular technique since the introduction of regional anaesthesia. Several drugs have been tried as local anaesthetic agents in subarachnoid block. Lignocaine was the first synthetic amino amide local anaesthetic ${ }^{1}$ and $5 \%$ hyperbaric lignocaine was used as spinal anaesthetic agent for a long time, later $0.5 \%$ hyperbaric Bupivacaine heavy was used and is still popular inspite of the prolonged motor blockade.

$5 \%$ hyperbaric Lignocaine heavy was used most of the time as a single shot technique but when it was used as a continuous spinal anaesthesia, certain disadvantages were observed including prolonged motor blockade, numbness, urinary retention and Transient Neurological Symptoms (TNS). Because of this problem, use of 5\% hyperbaric lignocaine was questioned and not recommended for continuous infusion. The phenomenon of TNS is 7-9 times higher following lignocaine than with bupivacaine ${ }^{2}$

Lignocaine heavy in the subarachnoid space has many advantages like predictable quick onset, dense sensory and motor block of short duration hence this drug is considered as a preferred choice in day care anaesthesia. ${ }^{9}$ The researchers have tried various other concentrations like $1 \%, 1.5 \%, 2 \%, 2.5 \%$ of hyperbaric lignocaine in subarachnoid block and presently $2 \%$ hyperbaric lignocaine is available for clinical use in day care anaesthesia.

Present study is aimed to know the advantages and disadvantages of $2 \%$ hyperbaric Lignocaine hydrochloride for spinal anaesthesia required for surgical procedures lasting less than 2 hours.

\section{AIM}

To study the effect of $2 \%$ hyperbaric lignocaine in subarachnoid block in patients undergoing infraumbilical surgeries.

\section{OBJECTIVES}

To determine:

1. Onset and maximal level of sensory blockade

2. Onset of motor blockade

3. Duration of motor blockade

4. Haemodynamic parameters

5. Side-effects if any 


\section{MATERIALS AND METHODS}

This study was planned to evaluate the effect of $2 \%$ hyperbaric lignocaine in subarachnoid block in patients undergoing elective surgical procedures under spinal anaesthesia in the hospital. After approval by institutional ethics committee a total of 60 consenting in-patients with mean age of 18-65 years were considered in this study. It was a prospective outcome study of 18 months duration. The parameters needed to calculate the sample size of 60 were arrived at after a pilot study involving 10 patients.

1.1 Inclusion Criteria

$\circ \quad$ ASA grade 1 and 2

$\circ \quad$ Age group between 18-65 years of both sexes 3. Elective surgeries under spinal anaesthesia

\subsection{Exclusion criteria:}

Patient refusal

ASA grade 3 and 4

Patients with coagulation abnormalities

Patients with significant spine abnormality

Patients with neurological deficit

All the patients were uniformly managed with regards to pre-anaesthetic evaluation, investigations and pre medications. All patients were pre-loaded with $500 \mathrm{ml}$ Ringer's lactate solution before surgery. $2 \%$ hyperbaric lignocaine $2 \mathrm{ml}(40 \mathrm{mg})$ was used as the spinal anaesthetic agent. $25 \mathrm{G}$ Quinke's spinal needle was used for lumbar puncture.

Pulse oximetry, Non-invasive Blood Pressure, ECG monitoring was instituted in all patients. A specially designed proforma was used to collect the data, which includes patient's particulars, indication for surgery, the anaesthetic details, intra-operative monitoring for haemodynamics, observation for side effects etc.

Onset and peak sensory blockade level was measured using pin - prick sensitivity at level of L1. Onset and duration of motor blockade was assessed using the Modified Bromage Scale. Mean blood pressure was recorded just before giving spinal anaesthesia and subsequently at 1 minute, 3 minute, 5 minute and every 10 minutes thereafter till the end of surgery. A specially designed checklist was used to evaluate postoperative transient neurological symptoms.

Changes in the physiological parameters were analysed using paired $t$ test for statistical significance.

\section{RESUlTS}

Table. 1 shows the characteristics of spinal block measured in our study. The mean age of the patients included in this study was $38.88 \pm 13.12$ years, the minimum age being 18 years and maximum age was 64 yrs. The mean duration of surgery was $52.92 \pm 21.358$ minutes with minimum time for surgery lasting 25 minutes to maximum time being 120 minutes. The mean time taken for onset of sensory block was $67.07 \pm 11.085$ seconds; the earliest onset being 48 seconds and the maximum time for onset was 86 seconds. The mean time taken for onset of motor blockade was $153.83 \pm 14.332$ seconds; minimum time being 130 seconds and maximum time taken was 180 seconds. The mean time for motor block duration was $62.33 \pm 8.610$ minutes, the minimum duration being 45 minutes and maximum time it lasted was 80 minutes.

Out of the 60 patients included in the study, $32(53.3 \%)$ were females and 28 were males $(46.7 \%)$ were males (Table 2). The mean age of the patients included in this study was $38.88 \pm 13.12$ years, the minimum age being 18 years and maximum age was 64 years (Fig. 1).

The Maximum height of sensory block achieved was T10 dermatomal level in 29 patients followed by T8 in 25 patients, one with T9 level, 5 had T6 level (Table 3).

The basal value of mean of Mean arterial pressure was $87.8 \pm 7.77 \mathrm{~mm} \mathrm{Hg}$ and the mean found at 1 minute after giving spinal anaesthesia was $86.87 \pm 7.67 \mathrm{~mm} \mathrm{Hg}$, after 3 minutes it was $86.9 \pm 7.64$ and at 5 minutes was $87.65 \pm 7.61$; this was found to be statistically significant but the difference was not much to be clinically significant and after 10,30,40,50,60 minutes the values were not statistically significant (Table 4). The mean arterial blood pressure reached the baseline by 10 minutes. The Mean arterial blood pressure shows increase at 2 hour reading 89.1 \pm 7.68 which corresponds to the wearing off of the duration of action of the spinal drug (Fig. $3)$. 
VI. FIGURES AND TABLES

Table 1: Spinal block characteristics

\begin{tabular}{|l|l|l|l|l|l|}
\hline & \multicolumn{1}{|c|}{ Age } & \multicolumn{1}{|c|}{$\begin{array}{c}\text { Duration of } \\
\text { Surgery(min) }\end{array}$} & $\begin{array}{c}\text { Sensory block Onset } \\
(\mathrm{sec})\end{array}$ & $\begin{array}{c}\text { Motor Block Onset } \\
(\mathrm{sec})\end{array}$ & $\begin{array}{c}\text { Motor Block } \\
\text { Duration (min) }\end{array}$ \\
\hline Mean & 38.88 & 52.99 & 67.07 & 153.83 & 62.33 \\
\hline Std. Deviation & 13.124 & 21.358 & 11.085 & 14.332 & 8.610 \\
\hline Minimum & 18 & 25 & 48 & 130 & 45 \\
\hline Maximum & 64 & 120 & 86 & 180 & 80 \\
\hline
\end{tabular}

Table 2: Sex distribution of participants

\begin{tabular}{|c|c|c|}
\hline Sex & No.s & Percentage \\
\hline Male & 28 & 46.7 \\
\hline Female & 32 & 53.3 \\
\hline Total & 60 & 100 \\
\hline
\end{tabular}

Table 3: Maximum level of sensory blockade

\begin{tabular}{|c|c|c|}
\hline Max. Height achieved & Sensory block & Percentage \\
\hline T10 & 29 & 48.3 \\
\hline T6 & 5 & 8.3 \\
\hline T8 & 25 & 41.7 \\
\hline T9 & 1 & 1.7 \\
\hline Total & 60 & 100 \\
\hline
\end{tabular}

Figure 1

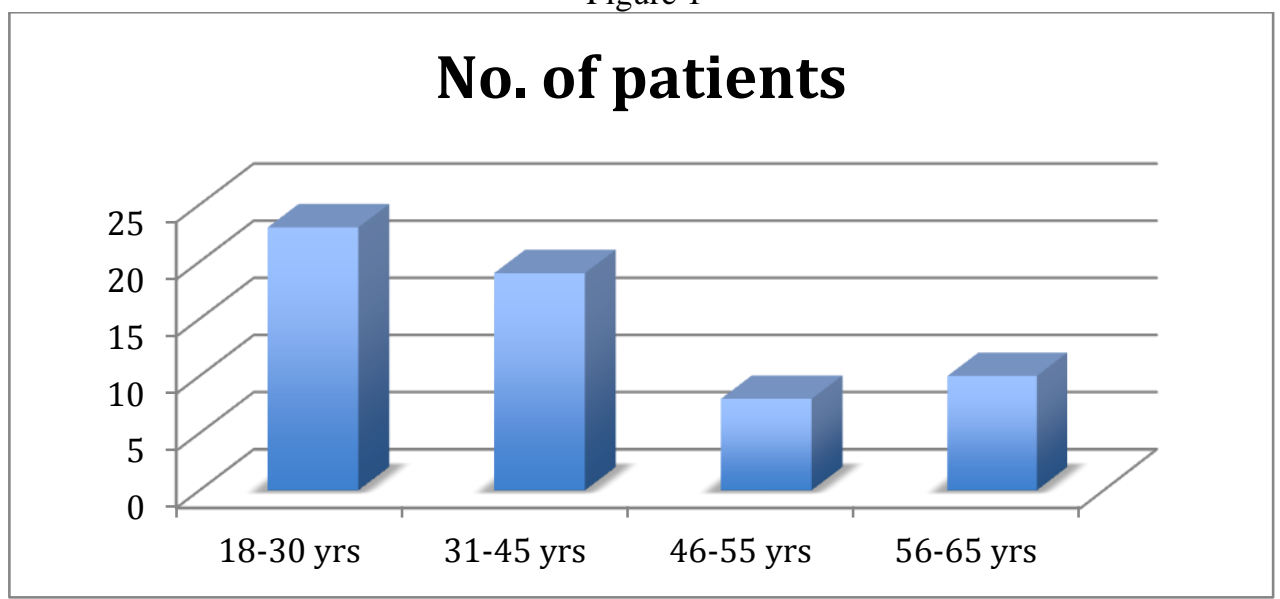

Figure. 1: Age distribution of the participants

Figure 2

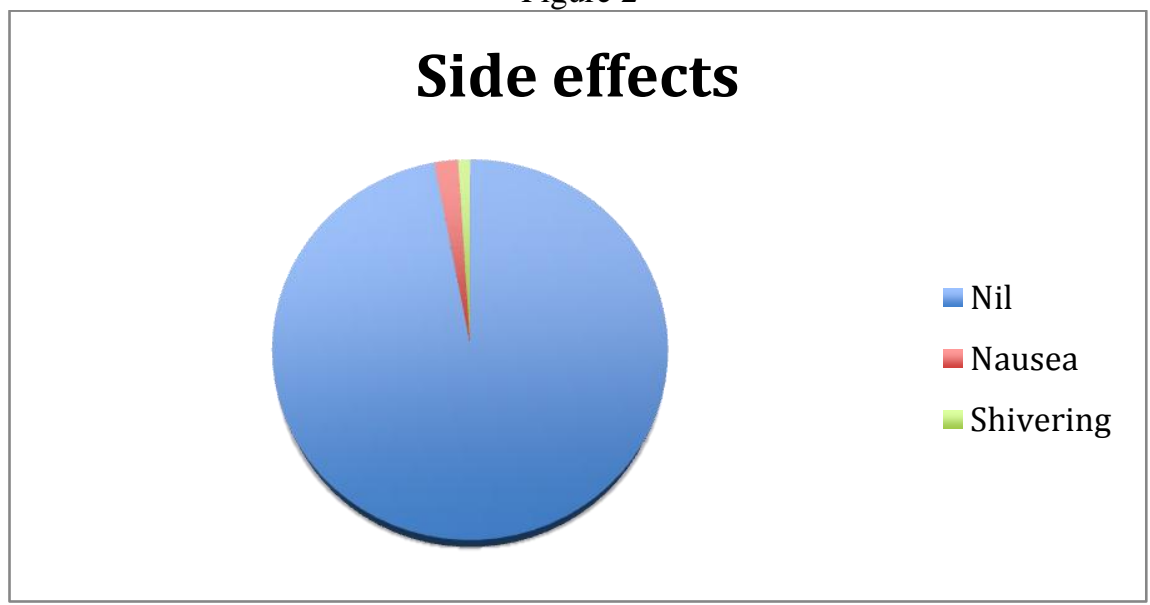

Figure. 2: Side effect profile of the participants 
Figure. 3

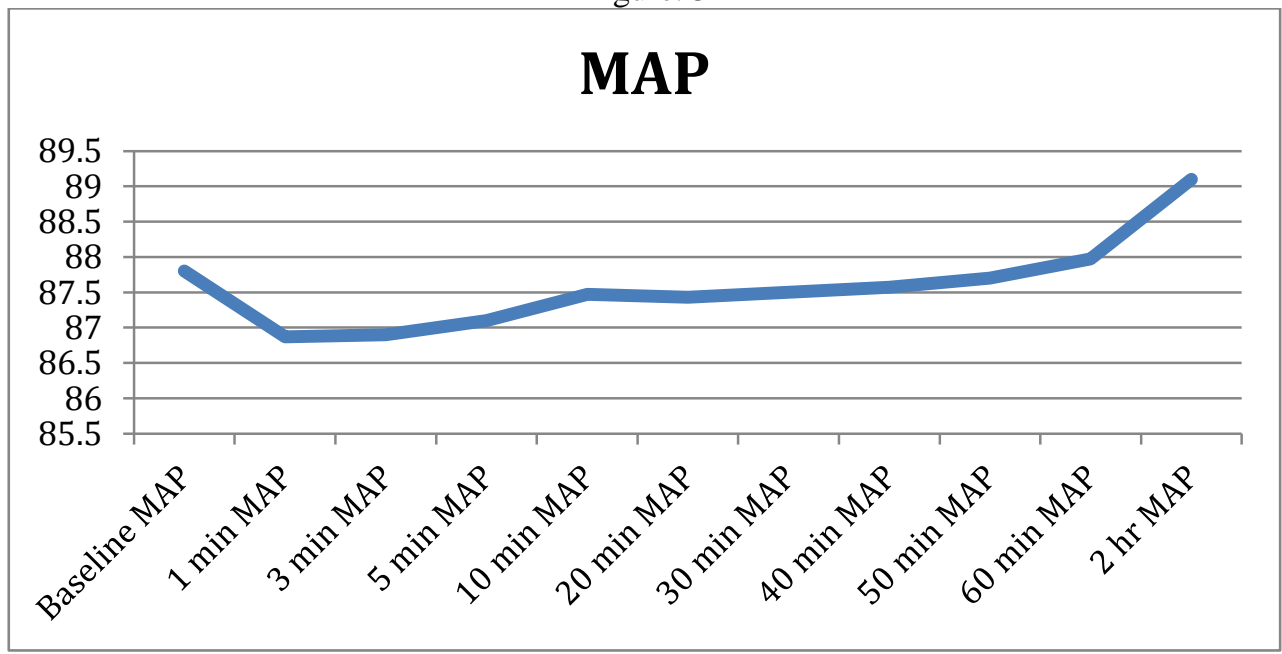

Figure. 3: Comapring baseline mean arterial pressure to other time periods

\section{DISCUSSION}

Centroneuraxis block results in sympathetic blockade, sensory analgesia and motor blockade (depending on dose, concentration and/or volumes of local anaesthetic) after insertion of a needle in the plane of the centroneuraxis. Spinal anaesthesia requires a small mass (i.e. volume) of drug, virtually devoid of systemic pharmacological effects to produce profound, reproducible sensory analgesia and superb skeletal muscle relaxation facilitating surgical exposure.

The present study comprised of 60 in patients aged between $18-65$ years of either sex of ASA grade 1-2 undergoing lower abdominal and lower limb surgeries lasting less than 2-hour duration. All the patients received $2 \%$ hyperbaric lignocaine $2 \mathrm{ml}(40 \mathrm{mg})$ as a sole spinal anaesthetic agent using $25 \mathrm{G}$ quincke needle after uniform pre-medication and pre-loading with $500 \mathrm{ml}$ of lactated Ringer's solution. Spinal block characteristics, haemodynamic effects and side effects were observed. Here are the analyses of the results.

The mean time taken for onset of sensory block was $67.07 \pm 11.085$ seconds; the earliest onset being 48 seconds and the maximum time for onset was 86 seconds. Punj $\mathrm{J}_{\text {et }} \mathrm{al}^{3}$ (2013) in their study compared the clinical efficacy of $2.5 \%$ hyperbaric lignocaine. Time to onset of sensory block in seconds was $62.50 \pm 25.05$.

1. Thus, sensory block onset time of $62.50 \pm 25.05$ seconds of $2.5 \%$ hyperbaric lignocaine was faster compared to $67.07 \pm 11.085$ seconds in our study where $2 \%$ hyperbaric lignocaine was used.

The mean time taken for onset of motor blockade was $153.83 \pm 14.332$ seconds, minimum time being 130 seconds and maximum time taken was 180 seconds. According to Punj $\mathbf{J}$ et al ${ }^{3}(2013)$ the mean onset of motor block in seconds with $2.5 \%$ hyperbaric lignocaine was $119.5 \pm 56.51$. Thus the onset of motor block was quicker in their study probably because they used $2.5 \%$ hyperbaric lignocaine and is comparative to our study.

The maximum height of the sensory block achieved ranged mostly between T10-T8. Among our study participants 29 patients had sensory blockade level of T10 and 25 patients had T8 as the highest level achieved. Williams $\mathrm{N}^{4}$ (1995) in their study found that in $2 \%$ lignocaine $3.5 \mathrm{ml}$, a sensory level of T10 was produced more quickly $(\mathrm{P}=0.0001)$ and maximum height reached sooner $(\mathrm{P}=0.0002)$ with lignocaine.

The mean time for motor block duration in our study was $62.33 \pm 8.61$ minutes, the minimum duration being 45 minutes and maximum time it lasted was 80 minutes. Harbers JB et al ${ }^{5}$ studied the effect of 4 ml of lidocaine $2 \%$ containing $8 \%$ glucose. Duration of complete motor blockade of the lower extremities was significantly shorter, $59.1 \pm 6.5$ minutes. The volume used was $4 \mathrm{ml}$ of $2 \%$ hyperbaric lignocaine compared to $2 \mathrm{ml}$ used in our study, the mean duration motor blockade was shorter, 59 minutes compared to 62 minutes obtained in our study despite of more volume.

The basal mean value of mean arterial pressure was $87.8 \pm 7.77 \mathrm{mmHg}$ and at 1 minute after giving spinal anaesthesia it was $86.87 \pm 7.67 \mathrm{~mm} \mathrm{Hg}$, after 3 minutes it was $86.9 \pm 7.64$ and at 5 minutes was $87.65 \pm 7.61$ and was found to be not clinically significant, but was statistically significant and after 10,30,40,50,60 minutes were not statistically significant. The mean arterial blood pressure reached the baseline by 10 minutes. The mean arterial blood pressure shows an increase at 2 hour reading $89.1 \pm 7.68$ which corresponds to the wearing off of the duration of action of the spinal drug.

According to J. Kristensen et al ${ }^{6} 4 \mathrm{ml}$ of $2 \%$ lignocaine glucose free produces: 1 .Quicker onset with greater decrease in systolic arterial pressure and slower heart rate.2.Faster sensory and motor resolution ensuring rapid return to normal cardiac performance before leaving the recovery room. 
Punj $\mathrm{J}^{3}$ concluded that for short duration surgeries lasting up to one hour, $2.5 \%$ lignocaine is a better choice as compared to 5\% lignocaine as the lower concentrated solutions of bupivacaine and lignocaine are more haemodynamically stable compared to their higher concentrations and with similar duration of sensory and motor block.

Williams $\mathrm{N}$ et al ${ }^{4}$ compared $2 \%$ lignocaine $3.5 \mathrm{ml}$ with $0.5 \%$ hyperbaric bupivacaine $3 \mathrm{ml}$ although there was a greater reduction in systolic arterial pressure and a trend towards slower heart rates. Return of full sensory and motor function occurred earlier with lignocaine.

There was not much change in the baseline Mean arterial blood pressure compared to the other time periods in our study. Prior Preloading with Ringer's solution prevented clinically significant fall in the Mean Arterial pressure.

It is clear that the low spinal anaesthesia (i.e at T10 or lower spinal level) carries different physiological impact than does a block performed to produce high (>T5) spinal anaesthesia. Low dose spinal anaesthesia has been advocated in the interest of maintaining cardio vascular stability especially in lower abdominal and perineal surgeries. Inadequate analgesia/pain relief in the perineal region is discomforting to the patient and can cause reflex inhibition of bladder evacuation.

There were no major adverse effects or neurological symptoms observed in this study population. Certainly none of the risk factors that increase the likelihood of TNS were present in our patients except the drug, lignocaine. As per Srivastava U et al ${ }^{7}$ neurotoxicity of all local anaesthetics has been known for many years in doses and concentration much greater than those used clinically.

The study shows that intrathecal $2 \%$ hyperbaric lignocaine is recommended as an excellent and safe modality for patients undergoing day care surgeries. The results from this study also supports previous research by the authors Chilvers $\mathrm{CR}^{8}$ et al i.e. absence of hypotension, rapid recovery and high patient acceptance with smalldose hyperbaric lignocaine spinal anaesthesia.

\section{CONCLUSION} arrived:

Study of $2 \mathrm{ml}$ of $2 \%$ hyperbaric lignocaine in 60 ASA I-II patients, the following conclusion was

Onset of sensory blockade was found to be $1.11 \pm 0.18$ minutes. The Maximal level of sensory blockade reached was T10 level in majority of the patients in study group. Onset of motor blockade was $2.56 \pm 0.23$ minutes. The Duration of motor block lasted was $62.33 \pm 8.61$ minutes.

Haemodynamic Parameters like Mean values of baseline and other time period's Heart rate, Systolic blood pressure, Diastolic blood pressure, Mean arterial pressure and Oxygen saturation although found statistically significant, the data showed no significance clinically.

Adverse effects like hypotension, bradycardia or neurological deficits related to the drug were not seen in this study.

Hence $2 \%$ hyperbaric lignocaine is found to be effective spinal anaesthetic agent for day care surgeries.

\section{REFERENCES}

[1] T.N Calvely \& N.E William, Principles \& Practice of pharmacology for anaesthetists-5th Ed (Blackwell Publishing, 2009)

[2] Dahl V, Gierloff C, Omland E, Raeder JC. Spinal, Epidural or propofol anaesthesia for out-patient knee arthroscopy? Acta Anaesthesiol Scand, 41(10), 1997 Nov, 1341-5.

[3] Punj J, Khan RM. Spinal anaesthesia for pelvic surgery: low concentrations of lignocaine and bupivacaine are effective with less adverse events. Middle East J Anesthesiol, 22(1), 2013 Feb, 71-7.

[4] Williams N, Doyle A, et al. Spinal anaesthesia for transurethral surgery: comparison of $2 \%$ lignocaine with hyperbaric $0.5 \%$ bupivacaine. Br J Anaesth. 75, 1995, 9-11.

[5] Harbers JB, Stienstra R, et al. A double blind comparison of lidocaine $2 \%$ with or without glucose for spinal anesthesia. Acta Anaesthesiol Scand. 39(7), 1995 Oct, 881-4.

[6] Kristensen J, Helbo- Hansen HS, Toft P, Hole P. Spinal anaesthesia with glucose-free $2 \%$ lignocaine. Effect of different volumes. Acta Anaesthesiol Scand. 33(1), 1989 Jan, 53-7.

[7] Srivastava U, Kumar A, Saxena S, Saxena R et al. Spinal anaesthesia with lignocaine and fentanyl. 48(2), 2004, 121-123.

[8] Chilvers CR, Vaghadia H, Mitchell GW, Merrick PM. Small-dose hypobaric lidocaine-fentanyl spinal anesthesia for short duration outpatient laparoscopy. II. Optimal fentanyl dose. Anesth Analg 1997; 84:65-70.

[9] Peng PW, Chan VW, Perlas A. Minimum effective anaesthetic concentration of hyperbaric lidocaine for spinal anaesthesia. Can J Anaesth 1998;45(2):122-29 